\title{
Does Normal Blood Glucose Level Have any Relation with Chin Dimple?
}

\author{
Muhammad Imran Qadir, Noor Arif* \\ Institute of Molecular Biology and Biotechnology, Bahauddin Zakariya University, Multan, Pakistan. \\ *Corresponding Author: Noor Arif, Institute of Molecular Biology and Biotechnology, Bahauddin \\ Zakariya University, Multan, Pakistan.
}

\begin{abstract}
Effect of normal blood sugar level on the presence or absence of dimple on chin was the objective of this study. Blood sugar level is the amount of glucose present in the blood in normal conditions or in fasting condition. A total of 110 undergraduate students of Bahauddin Zakariya University, Multan, Pakistan took part in this activity. The research was about the effect of normal blood sugar level on chin's dimple. Blood sugar level was checked. It was concluded from the research that there was no effect of normal glucose level on the dimple on chin.
\end{abstract}

Keywords: sugar level, hyperglycemia, diabetes, Glyceamic index, glucometer

\section{INTRODUCTION}

The sugar level in blood, concentration of sugar in blood and level of glucose in blood is the volume of glucose currently present in the body of humans. $70 \mathrm{~kg}$ human's blood contains 4 grams of glucose. Glucose is stored in the form of glycogen in different body parts of humans such as liver and muscles. For the normal functioning of body, glucose is the main source of energy. $60 \%$ of glucose level in blood is consumed by the human's brain. Bloodstream is the main source for transport of glucose from one part of the body to the other. Glucose levels are normally least in the first part of the day, prior to the primary feast of the day, and ascend after supper for an hour or two by a couple millimoles.

High level or low level of glucose in body cause many diseases as hyperglycemia or hypoglycemia, respectively. There is another disease named as Diabetes that is due to the constant high level of glucose in blood due to many reasons. The level of glucose is measured in millimoles per liters or also measured in milligrams per deciliters (1).

For non-diabetic patients, the level of glucose in blood is normal that is in the range of 3.9 to 7.1 millimole per liter. The level of glucose is not constant throughout the day. After taking meal, the level of glucose in body suddenly rises to $7.8 \mathrm{mmol} / \mathrm{L}$ in non-diabetic patients while $10 \mathrm{mmol} / \mathrm{L}$ in diabetic patients that is the risk factor for them. So, after taking meal for diabetic patients, the glucose level should be less than $10 \mathrm{mmol} / \mathrm{L}$.

Homeostatic process of the body keeps level of glucose in blood inside a tight range. Different types of hormones are present in body that affects the level of glucose in body and these hormones are incompatible to each other. These hormones are catabolic hormones and anabolic hormones. Catabolic hormones include glucagon that causes the increase of glucose level in blood while anabolic hormones include insulin that lowers the level of glucose in blood in case of hyperglycemia. Epinephrine and cortisol hormones are also present in the body that along with other hormones regulate the level of glucose in blood and keeps it stable.

Fluctuating level of glucose in blood cause many aberrations. Long term high level of glucose causes hyperglycemia that leads to long-lasting problems. Diabetes is the cause of hyperglycemia. About 2$5 \%$ of our population is affected with this disease and doctors advise the anti-diabetic pills for medication. Hyperglycemia occurs due to low glucose level. Indications may include dormancy, weakened mental working; peevishness; shaking, jerking, shortcoming in arm and leg muscles; pale appearance; perspiring; loss of awareness. 
The level of sugar in blood can be controlled by exercise and diet. Healthy food and low GI level can cause reduce in sugar level and different complications in body. GI is the Glyceamic Index that is the effect on sugar level due to presence of carbohydrates in food. Glucose level can also be controlled by the physical activities.

If when body is influenced by sort 2 diabetes, medicine might be utilized to deal with the body condition. Factors, for example, diet, exercise and loss of weight are vital in overseeing blood sugars - if body have endeavored to make changes but not effective in increasing great control of level of blood sugars, there are numerous kinds of drugs that can enable to deal with the diabetes. These prescriptions are typically taken orally, to enable lower to glucose levels. There are distinctive classes of prescriptions, which deal with various parts of the body, to attempt and adjust the dimensions of insulin and sugar in the body.

A cleft in chin or dimple on chin is a Y-formed dimple in the center. It's generally a hereditary characteristic. Contingent upon your inclination, you may consider it as an indication of beauty or not. You can both include and evacuate a separated jaw with medical procedure, additionally called mentoplasty (2). A few people who have dimple hatred it since they trust it's ugly. They take a gander at it as a flaw. In any case, they are in truth eye-catching. The split jaw or dimpled jaw can be brought about by hereditary qualities. There is nothing too confounded about the science behind it. Since the mentalis muscle neglects to close at the jaw, it leaves a hole. That hole is the adorable thing we term jaw dimple (3).

Effect of normal blood sugar level on the presence or absence of dimple on chin was the objective of this study.

\section{MATERiAls AND METHODS}

\subsection{Measurement of Blood Sugar Level}

For measuring the blood glucose level at home, we must arrange our kit. The kit contains glucometer, test strips box, finger pricker and tissue paper or cotton to wipe the drops of blood. Prior to start the experiment, we must appropriately wash our hands and dry them. Now take one strip from the box and place it in the glucometer. Now switch on the machine. Always prick at the side of the finger as it is less painful than the tip of the finger. Now prick the finger and lightly squeeze it with help of other fingers. Now put the blood onto the strip of glucometer and the results will appear in few seconds and the machine will show us the blood glucose level of blood at that time. Now clean the blood drop with the help of tissue paper or cotton and remove the test strip and threw it. Note down the blood glucose level.

\subsection{Project Design}

A total of 110 undergraduate students of Bahauddin Zakariya University, Multan, Pakistan took part in this activity. The research was about the effect of normal blood sugar level on chin's dimple.

M-STAT was used to analyze statistical analysis.

\section{RESUltS}

Effect of blood glucose level is given in figure.1. This graph showed that the high ratio of presence of dimple on chin was in males and its standard deviation was also high that was 8.46. $t$-test was also applied and the overall results were observed that were non-significant. This showed that there was no effect of glucose level on dimple on chin.

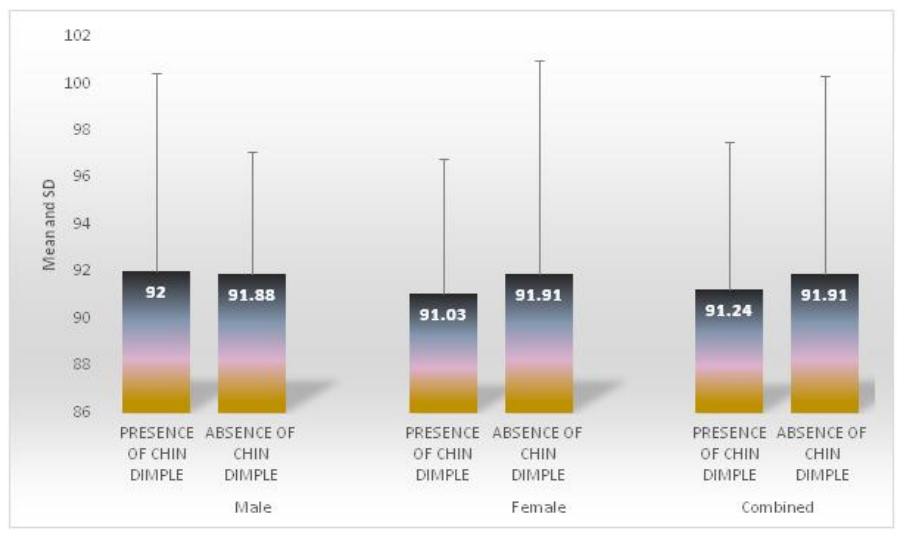

Figure1. Effect of sugar level on dimple on chin (Mean $\pm S D$ ) 
Figure1. Effect of sugar level on dimple on chin ( $p$ value)

\begin{tabular}{|c|c|c|c|}
\hline \multirow{2}{*}{$p$ value } & Male & Female & Combined \\
\cline { 2 - 4 } & 0.97 & 0.57 & 0.63 \\
\hline
\end{tabular}

$p>0.05$ that were non-significant results

\section{DISCUSSION}

Recent studies have given an important advancement in research (4-10)

Tsuneki, Ishizuka, Terasawa, did a study on the level of glucose on the body due to green tea and they also studied about the serum proteomics in diabetes. They recommended that type 2 of diabetes is due to utilization of green tea. The investigation was gone for giving proof of enhancement in digestion of glucose in mice having diabetes and people in good physical shape upon green tea utilization. Digestion of glucose can be prompted by green tea utilization in human at $1.5 \mathrm{~g} /$ body in glucose tests. Level of glucose in blood can be brought down by the consumption of green tea in diabetic mice while no impact was seen in control mice. It was proved that green tea had an influence that is against the diabetes. Although they couldn't find out the inspiration of green tea on the diabetes-incited alterations. They saw that protein level diminished because of utilization of green tea. They observed that serum protein might be correlated with the anti-hyper glycaemia effect of green tea (11).

Level of glucose in mice is also studied and it was done by Rerup and Lundquist. Various sequential glucose level in blood judgments in individual mice were performed on little blood tests utilizing the orbital draining method. Glucose was set clearly by a known enzymatic response. Blood glucose decided along these lines was discovered a parameter of high reproducibility. In the testing method in that capacity, intravenous saline infusion did not really have any impact on the level of the glucose in the blood, though understanding of slight glucose changes under trial conditions ought to dependably be founded on an examination with control gatherings? In typical non-fasting mice critical contrasts in homoeostatic blood glucose level modifications were illustrated. Levels of glucose in mice were lower and more factor than in normal individuals (12).

Benton and Owens did a study on the blood glucose level and memory. They studied that either there is a relation between glucose level and memory of human. Blood glucose may take up a job in the movement of some personal upgrading drugs; the influence of carbonated drinks on human memory was scrutinized. In a twofold visually impaired investigation the impact was analyzed of a beverage containing fifty (50) g glucose. Critical connection was investigated between the level of glucose in blood and the number of words reviewed. People with high level of glucose recall a greater number of words than the people with low level of glucose. They observed that there is no relation of glucose level with memory. Second survey was done in which they report about the consumption of carbonated drinks for 2 hours. The glucose-instigated enhancement happened independent of starting blood glucose level (13).

\section{CONCLUSION}

It was concluded from the overall research that there was no effect of normal glucose level on the dimple on chin.

\section{REFERENCE}

[1] Matsumoto N, Ishigaki F, Ishigaki A, Iwashina H, Hara Y. Reduction of blood glucose levels by tea catechin. Bioscience, biotechnology, and biochemistry. 1993 Apr 23; 57(4):525-7.

[2] Boo-Chai K. The facial dimple-Clinical study and operative technique. Plastic and Reconstructive Surgery. 1962 Aug 1; 30(2):281-8.

[3] Daponte AP, Vienna A, Brant L, Hauser G. Cheek dimples in Greek children and adolescents. International Journal of Anthropology. 2004 Oct 1; 19(4):289-95.

[4] Qadir MI, Saba G (2018) Awareness about intestinal cancer in university student. Nov Appro in Can Study, 1(3): NACS.000515.2018.

[5] Qadir MI, Ghalia BA (2018) Awareness survey about colorectal cancer in students of M. Phil Biotechnology at Bahauddin Zakariya University, Multan, Pakistan. Nov Appro in Can Study, 1(3): NACS.000514.2018.

[6] Qadir MI, Rizvi M (2018) Awareness about thalassemia in post graduate students. MOJ Lymphology \& Phlebology, 2(1): 14-16. 
[7] Qadir MI, Shahzad R (2018) Awareness about obesity in postgraduate students of biotechnology. Int J Mod Pharma Res, 7(2): 14-16.

[8] Qadir MI, Mehwish (2018) Awareness about psoriasis disease. Int J Mod Pharma Res, 7(2): 17-18.

[9] Qadir MI, Ishfaq S (2018) Awareness about hypertension in biology students. Int J Mod Pharma Res, 7(2): $08-10$

[10] Qadir MI, Saleem A (2018) Awareness about ischemic heart disease in university biotechnology students. Glo Adv Res J Med Medical Sci, 7(3): 059-061.

[11] Tsuneki H, Ishizuka M, Terasawa M, Wu JB, Sasaoka T, Kimura I. Effect of green tea on blood glucose levels and serum proteomic patterns in diabetic $(\mathrm{db} / \mathrm{db})$ mice and on glucose metabolism in healthy humans. BMC pharmacology. 2004 Dec; 4(1):18.

[12] Rerup C, Lundquist I. BLOOD GLUCOSE LEVEL IN MICE. Acta endocrinologica. 1966 Jul 1; 52(3):357-67.

[13] Benton D, Owens DS. Blood glucose and human memory. Psychopharmacology. 1993 Nov 1; 113(1):83$8 . s$

Citation: Muhammad Imran Qadir, Noor Arif, "Does Normal Blood Glucose Level Have any Relation with Chin Dimple?" International Journal of Research Studies In Biosciences (Ijrsb), Vol. 7, no. 4, pp. 1-4, 2019. http://Dx.Doi.org/10.20431/2349-0365.0704001

Copyright: (C) 2019 Authors. This is an open-access article distributed under the terms of the Creative Commons Attribution License, which permits unrestricted use, distribution, and reproduction in any medium, provided the original author and source are credited. 